\title{
ГЕОМЕХАНИЧЕСКАЯ ОЦЕНКА ПАРАМЕТРОВ УСТОЙЧИВОСТИ ОТКОСОВ БОРТОВ И УСТУПОВ ПРИ ОТРАБОТКЕ МЕСТОРОЖДЕНИЯ АПАТИТ-НЕФЕЛИНОВЫХ РУД «ОЛЕНИЙ РУЧЕЙ»
}

\author{
Немова Наталья Анатольевна', \\ nemova-nataly@mail.ru \\ Бельш Татьяна Александровна',
tata0303@bk.ru \\ ' Институт горного дела им. Н.А. Чинакала Сибирского отделения Российской академии наук,
Россия, 630091, г. Новосибирск, Красный пр., 54.
}

Актуальность обусловлена необходимостью безопасного ведения горных работ на карьерах глубиной свыше 360м. Наращивание объёмов добычи возможно при значительном углублении; для снижения объёмов вскрыши необходимо укручение откосов бортов и уступов. Для решения данного вопроса необходимо знать геомеханическую обстановку уступов и бортов как на предельном контуре, так и при изменении их основных параметров - высоты и углов наклона.

Цель: проанализировать горно-геологические условия месторождения «Олений ручей» и существующие данные о физико-механических свойствах горных пород, слагающих массив рассматриваемого месторождения, произвести расчет и проверку устойчивости откосов бортов карьера на предельном контуре и изыскать возможность укручения откосов бортов и вскрышных уступов при ведении горных работ.

Объект: крупное месторождение апатит-нефелиновых руд «Олений ручей».

Методы: горно-геологический анализ месторождения "Олений ручей» и анализ существующих данных о физико-механических свойствах горных пород, слагающих массив рассматриваемого месторождения, аналитические расчеты устойчивости элементов ОТКоСов.

Результаты. Получены данные расчетов устойчивости откосов при отсутствии поверхностей ослабления в прибортовом массиве борта в висячем боку рудной залежи (висячий борт) и с учетом угла падения Главного разлома под углом 40-45 при формировании борта в лежачем боку (лежачий борт), а также с учетом сейсмичности района и уровня грунтовых вод. Определены параметры откосов бортов на предельном контуре. Полученные значения параметров правомерны при отсутствии в прибортовом массиве поверхностей ослабления. При наличии поверхностей ослабления с падением в выработку откосы необходимо заоткашивать строго по этим поверхностям.

\section{Ключевые слова:}

Карьер, рудник, борт, уступ, откос, угол наклона (борта, уступа), прибортовые запасы, массив горных пород, геомеханическое обоснование, напряженно-деформированное состояние, устойчивость, коэффициент запаса, разрушение, система разработки, безопасность, эффективность.

\section{Введение}

На протяжении последних 10 лет в Хибинах осваивается крупное месторождение апатит-нефелиновых руд «Олений ручей», находящееся в юговосточной части Хибинского горного массива, а с северо-востока примыкает к Ньоркпакхскому месторождению. Месторождение пространственно приурочено к участку выклинивания ийолит-уртитового комплекса. Со стороны лежачего бока продуктивная зона месторождения контактирует с рисчорритами, а также с Ньоркпахкским месторождением в зоне сопряжения и с хибинитами. Висячий бок со стороны центра Хибинского массива слагают рисчорриты и фойяиты $[1,2]$. На юго-западном фланге месторождения наблюдается максимальная мощность продуктивной зоны, где она имеет ширину $1,7 \mathrm{\kappa м}$; на северо-востоке ее ширина составляет не более 200 м в районе разведочной линии 19 [3]. Общее падение элементов внутренней структуры продуктивной зоны и ее внешних контактов направлено к центру массива, угол падения составляет $30-40^{\circ}$ на юго-западе, увеличиваясь до $60-70^{\circ}$ на северо-востоке [4]. Продуктивная зона имеет сложное многоярусное строение, обусловленное чередованием в разрезе пластообраз- ных тел апатит-нефелиновых руд, трахитоидных уртитов, ийолитов, мельтейгитов, массивных уртитов и ювитов, нефелиновых сиенитов, а также останцов более древних рисчорритов. Проектом предусмотрена отработка месторождения открытым способом [5-7].

В последние годы глубина карьеров значительно увеличивается, что приводит к наращиванию объёмов добытой руды и вскрышных пород на месторождениях. Снижение объёма вскрышных пород возможно только за счёт с укручения углов откосов бортов и уступов [8]. С другой стороны, горно-геологические условия ухудшаются с глубиной, что связано с изменением как физико-механических свойств вмещающих пород, так и их напряженно-деформированного состояния. Например, самыми глубокими карьерами в мире считаются: карьер «Bingham-Canyon», известный также как «Kennecott Copper Mine», расположенный на Западе США и разрабатывающий гигантское меднопорфировое месторождение открытым способом и имеющий глубину 1200 м; карьер «Chuquicama$t a »$, отрабатывающий месторождение меди, находящийся в центральных Андах на высоте 2840 м, на севере Чили, в 240 км к северо-востоку от горо- 
да Антофагаста, глубиной более 850 м; карьер «Палабора», отрабатывающий карбонатитовое месторождение в ЮАР глубиной около 700 м; медный рудник «Эскондида», расположенный в пустыне Атакама, Чили, его глубина 645 м; карьер "Филистон», расположенный на юго-восточной окраине города Калгурли, Западная Австралия, его глубина достигает 600 м и др. [9]. Глубина карьеров, расположенных в России, уже превысила отметку 400 м: алмазный рудник «Удачный», находящийся в Восточно-Сибирском регионе России, добыча которого на глубине 640 м в кимберлитовой трубке продолжается с 1971 г.; рудники «Железный» АО «Ковдорский ГОК» и «Центральный» АО "Апатит», расположенные на Кольском полуострове, имеют глубину 450 и 590 м соответственно; "Восточный» - самый крупный карьер по добыче золота в РФ глубиной 580 м, находящийся в Красноярском крае; "Коркинский», самый глубокий угольный разрез Евразии, расположенный в Челябинской области, глубиной 500 м. И в этих сложных горно-геологических условиях повышенного внимания требует в первую очередь безопасность ведения горных работ на глубоких и очень глубоких карьерах [10].

Как и для других месторождений Хибин, напряженное состояние массива месторождения «Олений ручей» относится к типу, определяемому как гравитационно-тектонический, причём горизонтальные напряжения в несколько раз превышают вертикальные [10-14].

На устойчивость бортов, формируемых при отработке запасов апатит-нефелинового месторождения «Олений ручей», в основном влияет структурно-тектоническое строение прибортовых массивов [11-14].

Для данного месторождения характерно наличие Главного разлома, который представляет собой интенсивно тектонизированную зону, залегающую субсогласно по отношению к рудной залежи (секущую ее под острым углом), осложненную многочисленными ветвящимися оперяющими нарушениями и сопровождающуюся интенсивным окислением с участием метеорных вод и катаклазом [15]. Угол падения Главного разлома составляет ориентировочно $40-45^{\circ}$. Поэтому формирование борта в лежачем боку рудной залежи необходимо производить с учетом угла падения Главного разлома под углом не круче $40-45^{\circ}$ [15].

Со стороны висячего бока рудной залежи Главный разлом и сопутствующие ему структуры не оказывают существенного влияния на состояние борта карьера. Все зафиксированные системы трещин не влияют на устойчивость борта карьера в целом, понижая устойчивость в наиболее неблагоприятных случаях отдельных уступов или части уступов путем образования локальных вывалов. При этом только одна система конических трещин «С» центриклинального залегания падает на восток и юго-восток под углом в среднем около $45^{\circ}$, но, не являясь эффективной для борта карьера в це- лом, может способствовать возникновению локальных вывалов в пределах отдельных уступов. Обеспечение устойчивости уступов со стороны висячего бока залежи в этом случае состоит в применении технологии щадящего взрывания при постановке борта рациональной конструкции в конечный контур и в укреплении локальных участков уступов в случае необходимости [15].

Поверхности ослабления с падением в сторону выработки необходимо своевременно выявлять и не допускать их подрезку.

На апатит-нефелиновом месторождении «Олений ручей» выделяются:

- четвертичные отложения;

- выветрелые породы;

- скальные породы.

Четвертичные породы залегают в долинах ручьев и представлены гравийно-галечниковыми отложениями, разнозернистыми песками с прослоями супесей и суглинков. Мощность их колеблется от 3-8 м (на склонах) до 40 м (в средней части долин).

Выветрелые (зона интенсивной трещиноватости) породы представлены рисчорритами, уртитами, ийолитами и ювитами.

Целью исследования является анализ горногеологических условий залегания рудных залежей и вскрышных пород месторождения «Олений ручей» и физико-механических свойств пород, слагающих массив рассматриваемого месторождения. На основе представленных результатов исследований произвести расчет устойчивости откосов бортов карьера и их элементов на предельном контуре, принятых в действующем проекте, и изыскать возможности укручения откосов бортов и вскрышных уступов при ведении горных работ.

Геомеханическая оценка параметров устойчивости откосов бортов и их элементов, принятых в действующем проекте

С целью оперативного и перспективного планирования горных работ при разработке месторождения проводится эксплуатационная разведка, в ходе которой выявлены новые рудные тела в приконтурной зоне за пределами конечного контура карьера.

Для того чтобы отработать новые рудные тела за пределами конечного контура карьера, необходимо произвести оценку вариантов отработки прибортовых и подкарьерных запасов с целью их полного извлечения. При проектировании технологии выемки прибортовых и подкарьерных запасов возникают наибольшие сложности, поскольку их отработка вызывает нарушение устойчивости уступов и борта карьера.

Прочностные характеристики горных пород апатит-нефелинового месторождения «Олений ручей», полученные геологами при испытании образцов, приведены в табл. 1 [16].

Расчетные прочностные характеристики массива горных пород зоны выветривания и ниже ее представлены в табл. 2. 
Для перевода значений сцепления пород в образце, приведенных в табл. 1, к значениям в массиве используется установленная зависимость значения сцепления горных пород в массиве от интенсивности трещиноватости [17]:

$$
C=\frac{C_{0}-C}{1+a \ln (H W)}+C^{\prime}
$$

или

$$
C=C^{\prime}+\left(C_{0}-C^{\prime}\right) \lambda_{0},
$$

где $C_{0}$ - сцепление в образце (табл. 1 ), т/ $\mathrm{M}^{2} ; C^{\prime}$ - сцепление по трещинам, $C^{\prime}=10,0$ т/ $/ \mathrm{m}^{2}$ (табл. 2 [17]); $\lambda_{0}-$ коэффициент структурного ослабления.

$$
\lambda_{0}=\frac{1}{1+a \ln (H W)},
$$

$H$ - глубина залегания пород, м; $W$ - средняя интенсивность трещиноватости участка горного массива (количество трещин на 1 погонный метр), для выветрелых пород принимаем $W=20$, для невыветрелых $W=0,5 ; a-$ коэффициент, зависящий от прочности пород в монолитном образце и характеpa трещиноватости (табл. 1 [17]). Выветрелые коренные породы $-a=10,0$. Коренные породы ниже зоны выветривания $-a=7,0$.

В результате проведенных расчетов установлено, что коэффициент структурного ослабления $\left(\lambda_{0}\right)$ для выветрелых скальных пород по данному месторождению составляет - 0,0163, для невыветрелых скальных пород - 0,0420.

Показатели прочностных свойств пород, с учетом структурного ослабления в массиве, представлены в табл. 2.

При расчетах устойчивости откосов бортов карьера, согласно действующим нормативным документам, в исходные прочностные характеристики массива горных пород должен вводиться соответствующий коэффициент запаса устойчивости, значение которого составляет для откоса борта открытой горной выработки на предельном контуре $\eta=1,3$, а для откосов уступа $\eta=1,5$ [17].
В соответствии с этим при расчетах устойчивости используются расчетные характеристики, определяемые по формулам, приведенным в [17]:

$$
\begin{gathered}
C_{\mathrm{p}}=\frac{C_{\mathrm{M}}}{\eta}, \\
\varphi_{\mathrm{p}}=\operatorname{arctg}\left(\operatorname{tg} \frac{\varphi_{\mathrm{M}}}{\eta}\right),
\end{gathered}
$$

где $C_{\mathrm{p}}$ - расчетное значение сцепления пород в массиве с учетом нормативного коэффициента устойчивости, т/м ${ }^{2} ; C_{\text {м }}$ - сцепление пород в массиве (табл. 2), т/ $\mathrm{M}^{2} ; \eta$ - нормативный коэффициент устойчивости; $\varphi_{\mathrm{p}}$ - расчетный угол внутреннего трения, градус; $\varphi_{\text {м }}$-угол внутреннего трения в массиве (табл. 2), градус.

Расчеты устойчивости откосов с учетом сейсмичности района расположения карьера и обводненности массивов приведены в табл. 3.

Для выполнения поверочных расчетов устойчивости откосов приняты физико-механические характеристики пород, приведенные в табл. 2.

Общее уравнение равновесия по потенциальной поверхности скольжения, определяющееся методом алгебраического сложения сил, имеет вид:

$$
\Delta T=\sum\left[\left(N_{i}-D_{i}\right) \operatorname{tg} \varphi_{i}+C_{i} l_{i}-T_{i}\right],
$$

где $l_{i}$ - длина наиболее напряженной поверхности скольжения в пределах расчетного блока, $\mathrm{m} ; \rho_{i}, C_{i}{ }^{-}$ расчетные характеристики прочности пород; $\varphi_{i}-$ угол наклона касательной к поверхности скольжения в середине основания блока; $D_{i}$ - результирующая сила давлений, $z a \operatorname{tg}(\varphi) / \cos (\varphi)$, т; $T_{i}, N_{i}$ - соответственно касательная и нормальная составляющие веса расчетного блока, определяются по следующим формулам:

$$
\begin{aligned}
N_{i} & =P_{i} \cos \varphi_{i}, \\
T_{i} & =P_{i} \sin \varphi_{i},
\end{aligned}
$$

\begin{tabular}{|c|c|c|c|c|c|c|c|c|}
\hline \multirow[b]{2}{*}{$\begin{array}{c}\text { Породы } \\
\text { Rocks }\end{array}$} & \multicolumn{2}{|c|}{$\begin{array}{l}\text { Предел прочности, МПа } \\
\text { Tensile strength, MPa }\end{array}$} & \multirow{2}{*}{\begin{tabular}{|c|} 
Коэффици- \\
ент хрупко- \\
сти, ед. \\
Fragility co- \\
efficient, ed.
\end{tabular}} & \multicolumn{2}{|c|}{$\begin{array}{c}\text { Угол внутр. трения, градус } \\
\text { Angle of internal friction, degree }\end{array}$} & \multirow{2}{*}{\begin{tabular}{|c|} 
Сцепление в \\
образце $\mathrm{C}_{0}$ \\
МПА \\
Coupling in the \\
sample $\mathrm{C}_{0}, \mathrm{MPa}$
\end{tabular}} & \multicolumn{2}{|c|}{$\begin{array}{l}\text { Коэфф. крепости, ед. } \\
\text { Strength coefficient, ed }\end{array}$} \\
\hline & $\begin{array}{c}\text { сжатию } \\
\text { compression }\end{array}$ & $\begin{array}{c}\text { растяжению } \\
\text { tensile }\end{array}$ & & $\varphi_{0}$ & $\begin{array}{c}\varphi \text { при } 0,5 \sigma_{\text {сж }} \\
\varphi \text { at } 0,5 \sigma_{\text {сот }}\end{array}$ & & $\begin{array}{l}\text { по Протодья- } \\
\text { конову М.М. } \\
\text { Protodiako- } \\
\text { nov M.M. }\end{array}$ & $\begin{array}{c}\text { по } \\
\text { Барону Л.И. } \\
\text { Baron L.І. }\end{array}$ \\
\hline $\begin{array}{l}\text { Рисчорриты } \\
\text { Rischorrity }\end{array}$ & 204 & 7,4 & 28 & 69 & 41 & 19,9 & 20 & 9 \\
\hline $\begin{array}{l}\text { Рисчоррит-ювиты } \\
\text { Rischorrit-yuvity }\end{array}$ & 98 & 3,9 & 25 & 68 & 40 & 10,4 & 10 & 6 \\
\hline $\begin{array}{l}\text { Ювиты } \\
\text { Yuvity }\end{array}$ & 199 & 7,4 & 27 & 68 & 41 & 19,7 & 20 & 9 \\
\hline $\begin{array}{l}\text { Ювиты лейкократовые } \\
\text { Yuvity lejkokratovye }\end{array}$ & 110 & 6,0 & 18 & 64 & 39 & 13,7 & 11 & 7 \\
\hline $\begin{array}{l}\text { Уртиты } \\
\text { Urtity }\end{array}$ & 111 & 4,5 & 25 & 67 & 40 & 11,3 & 11 & 6 \\
\hline $\begin{array}{l}\text { Мончикиты } \\
\text { Monchikity }\end{array}$ & 276 & 16,6 & 17 & 62 & 39 & 34,7 & 28 & 13 \\
\hline
\end{tabular}

где $P_{i}$ - вес элементарных блоков, на которые разделяется призма в примыкающем к откосу массиве, ограниченная наиболее напряженной поверх-

Таблица 1. Прочностные характеристики горных пород

Table 1. Strength characteristics of rocks 
Таблица 2. Расчетные прочностные характеристики массива горных пород

Table 2. $\quad$ Calculated strength characteristics of rock mass

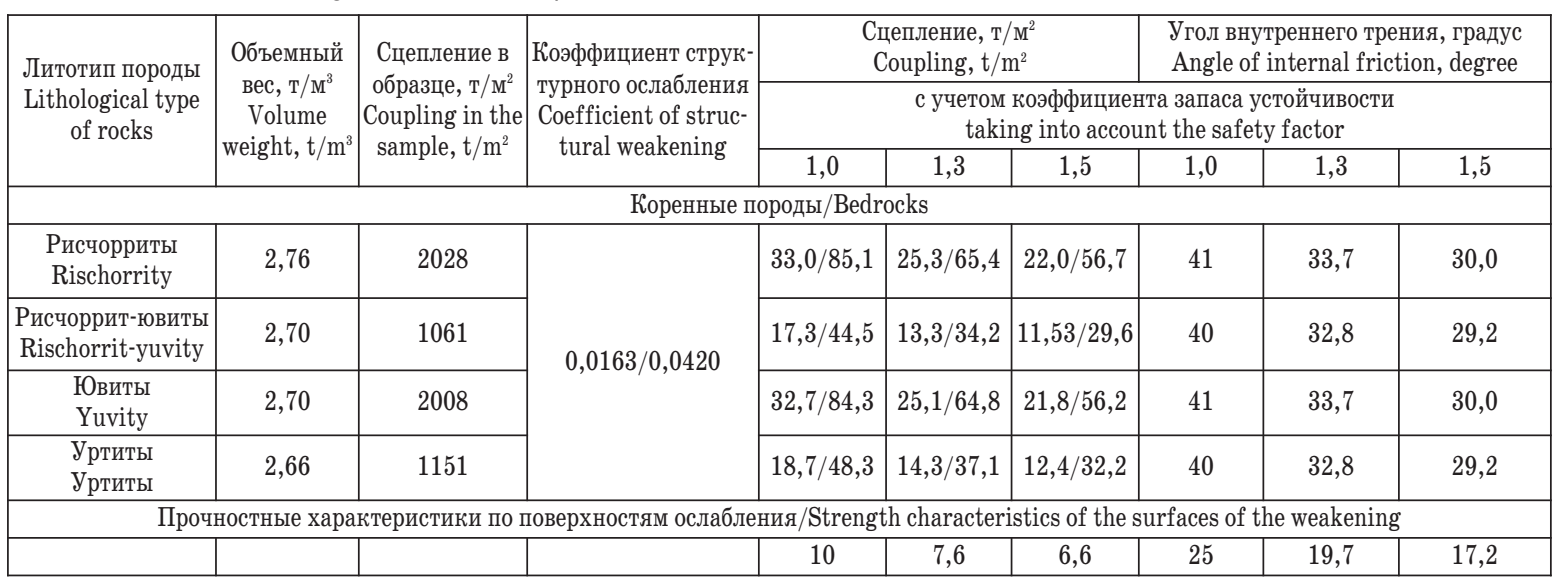

Прилечание: 1) в числителе приведены значения коэффициента структурного ослабления и свойства пород зоны интенсивной трещиноватости; в знаменателе - ниже зоны интенсивной трещиноватости; 2) корректировка исходных данных и недостающие данные по физико-механическим свойствам приняты на основании исследований; 3) значения объемного веса и угла внутреннего трения пород зоны интенсивной трещиноватости и пород, залегаемых ниже этой зоны, ввиду отсутствия данных для зоны интенсивной трещиноватости, приняты одинаковыми.

Note: 1$)$ the numerator shows the values of the coefficient of structural weakening and the properties of the rocks of the zone of intense fracturing; in the denominator - below the zone of intense fracturing; 2) adjustment of the initial data and missing data on physicomechanical properties taken on the basis of the research; 3 ) the values of the volume weight and the angle of internal friction of the rocks of the zone of intense fracturing and rocks lying below this zone, due to the lack of data for the zone of intense fracturing, are assumed to be the same.

ностью, т; $\sin (\varphi)-\sin$ угла наклона площадки, градус; $\cos (\varphi)$ - $\cos$ угла наклона площадки, градус;

$$
P_{i}=\gamma a_{i} h_{i},
$$

$y_{i}$ - средняя ордината кривой скольжения в пределах блока; $a_{i}$ - ширина расчетного блока, м; $\gamma-$ объемный вес пород в расчетном блоке, $\left(\mathrm{T} / \mathrm{m}^{3}\right) ; h_{i}-$ высота расчетного блока.

Массив находится в предельном состоянии, если разность удерживающих и сдвигающих сил $\Delta T$ равна нулю по наиболее напряженной поверхности.

Коэффициент запаса $n$ устойчивости откоса определялся для наиболее напряженной поверхности скольжения по формуле методом алгебраического сложения сил:

$$
n=\frac{\sum\left[\left(N_{i}-D_{i}\right) \operatorname{tg} \rho_{i}+C_{i} l_{i}\right]}{\sum T_{i}},
$$

где $\rho_{i}-$ угол внутреннего трения пород, градус.

Величина сейсмичности определяется по соответствующим схематическим картам СНиП II-7-81* [18].

таблица 3. Значения коэффициента сейсмичности

\begin{tabular}{|c|c|c|c|c|c|c|}
\hline $\begin{array}{l}\text { Показатель } \\
\text { Indicator }\end{array}$ & \begin{tabular}{|l} 
Ед. изм. \\
Unit
\end{tabular} & \multicolumn{5}{|c|}{$\begin{array}{c}\text { Значения } \\
\text { Values }\end{array}$} \\
\hline $\begin{array}{l}\text { Расчетная сейсмичность } \\
\text { Estimated seismicity }\end{array}$ & $\begin{array}{l}\text { Балл } \\
\text { Рoint }\end{array}$ & 6 & 7 & 8 & 9 & 10 \\
\hline $\begin{array}{l}\text { Коэффициент сейсмично } \\
\text { Seismicity coefficient }\end{array}$ & $m$ & 0,01 & 0,025 & 0,05 & 0,10 & 0 \\
\hline
\end{tabular}

Table 3. Values of the seismicity coefficient
Сейсмическая сила для каждого расчетного блока (отсека) принимается равной произведению веса отсека на коэффициент сейсмичности $m$, определяемый согласно табл. 3 [19].

Для условий района расположения месторождения коэффициент сейсмичности принимается $m=0,025$ (7 баллов).

Коэффициент запаса $n$ устойчивости откоса с учетом сейсмичности определялся по формуле:

$$
n=\frac{\sum\left[\left(N_{i}-m P_{i} \sin \varphi_{i}\right) \operatorname{tg} \rho_{i}+C_{i} l_{i}\right]}{\sum T_{i}+\Sigma P_{i} m \cos \varphi_{i}} .
$$

Коэффициент запаса устойчивости откоса $\eta$ с учетом влияния сейсмических нагрузок и силы гидростатического давления определялся по формуле:

$$
n=\frac{\sum\left[\left(N_{i}-D_{i}-m P_{i} \sin \varphi_{i}\right) \operatorname{tg} \rho_{i}+C_{i} l_{i}\right]}{\sum T_{i}+\Sigma P_{i} m \cos \varphi_{i}} .
$$

Критерием оценки обеспечения устойчивости откосов является соблюдение условия равновесия сдвигающих и удерживающих сил, выражаемых формулой Г.Л. Фисенко

$$
\eta=\frac{\sum F_{\text {уд }}}{\sum F_{\text {сдв }}},
$$

где $\eta$ - коэффициент запаса устойчивости; $F_{\text {уд }}-$ сумма удерживающих сил; $F_{\text {сд }}$ - сумма сдвигающих сил по поверхностям скольжения.

Ниже приводится характеристика состояния горного массива при разных значениях величин $\eta$ : - $\eta>1,5-2,0$ - горный массив не подвержен деформациям; 
- $\eta \geq 1,3-1,5$ - в прибортовых массивах могут отмечаться преимущественно упругие относительные горизонтальные деформации не более $1 \cdot 10^{-3}[17]$

- $\eta=1,2-1,3$ - относительные горизонтальные деформации могут достигать $(2-5) \cdot 10^{-3}$;

- $\eta=1,1-1,2$ - появляются заколы, горизонтальные деформации достигают $30 \cdot 10^{-3}$, а общие величины смещений - до 1,5-2,0 м;

- $\eta=1,0-1,1-$ прибортовой массив находится в состоянии предельного равновесия;

- $\eta<1,0$ - состояние прибортового массива оценивается как неустойчивое.

При оценке устойчивости откосов бортов и их элементов на предельном контуре коэффициент запаса устойчивости, в соответствии с рекомендациями нормативной документации [17], должен составлять не менее:

- $\eta=1,3$ - для бортов карьерной выемки;

- $\eta=1,5$ - для уступов, сложенных трещиноватыми породами, при сроке стояния до 5 лет, и не менее $\eta=2,0$ - для уступов со сроком стояния более 5 лет [17].

Расчет устойчивости бортов произведен согласно «Методическим указаниями ...». Расчёты устойчивости по определению параметров откосов бортов выполнены методом алгебраического сложения сил [17].

Поверхность скольжения в однородном массиве, примыкающем к откосу, построена с учетом ширины возможной призмы обрушения $(\mathrm{AB})$ и высоты вертикальной трещины отрыва $\left(H_{90}\right)$ :

$$
A B=\frac{2 H\left[1-\operatorname{ctg} \alpha \cdot \operatorname{tg}\left(\frac{\alpha+\rho}{2}\right)\right]-2 H_{90}}{\operatorname{ctg} \varepsilon+\operatorname{tg}\left(\frac{\alpha+\rho}{2}\right)},
$$

где $H$ - высота откоса, м; $\alpha$ - угол откоса, градус; $\varepsilon$ - угол элементарных площадок скольжения к направлению наибольшего главного напряжения, градус.

$$
\begin{aligned}
& H_{90}=\frac{2 \kappa}{\gamma} \operatorname{ctg} \varepsilon ; \\
& \varepsilon=45^{\circ}-\rho / 2 .
\end{aligned}
$$

\section{Оценка устойчивости откосов бортов на предельном} контуре, соответствующем проектным решениям

Результаты поверочных расчетов запаса устойчивости бортов приведены в табл. 4 .

Поверочные расчеты устойчивости откосов бортов на проектном предельном контуре и по варианту отработки по характерным профильным линиям (табл. 4) показали, что их устойчивость в основном обеспечивается нормативным коэффициентом запаса устойчивости $(\eta=1,3)$. Исключением являются участки северо-западного борта в висячем боку (в его нижней части) по пр.л. 29 и 33. таблица 4. Сводная таблица расчета коэффициента запаса устойчивости бортов (нормативный коэффициент запаса устойчивости $\eta=1,3$ )

\begin{tabular}{|c|c|c|c|c|c|c|c|c|}
\hline \multirow[b]{2}{*}{ 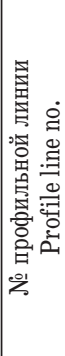 } & \multirow[b]{2}{*}{ 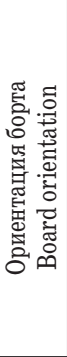 } & \multirow[b]{2}{*}{ 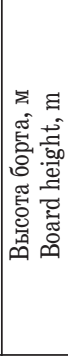 } & \multirow[b]{2}{*}{ 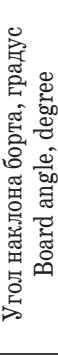 } & \multirow[b]{2}{*}{ 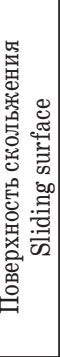 } & \multirow[b]{2}{*}{ 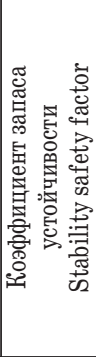 } & \multicolumn{3}{|c|}{$\begin{array}{c}\text { Коэффициент запаса } \\
\text { устойчивости с учетом } \\
\text { Stability factor with regard to }\end{array}$} \\
\hline & & & & & & 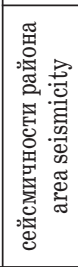 & 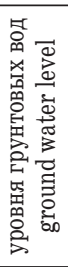 & 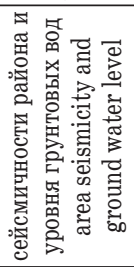 \\
\hline \multirow{7}{*}{ คి } & \multirow{4}{*}{ C3 } & 328 & 41 & S1 & $>1,5$ & $>1,5$ & 1,48 & 1,41 \\
\hline & & 282 & 50 & S2 & $>1,5$ & 1,49 & 1,39 & 1,33 \\
\hline & & 165 & 53 & S3 & $>1,5$ & $>1,5$ & 1,37 & 1,30 \\
\hline & & 43 & 75 & S4 & 1,31 & 1,27 & - & - \\
\hline & \multirow{3}{*}{ ЮВ } & 283 & 37 & S1 & $>1,5$ & $>1,5$ & $>1,5$ & $>1,5$ \\
\hline & & 207 & 42 & S2 & $>1,5$ & $>1,5$ & $>1,5$ & $>1,5$ \\
\hline & & 58 & 65 & S3 & 1,38 & 1,33 & - & - \\
\hline \multirow{3}{*}{ 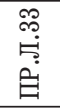 } & \multirow{3}{*}{ C3 } & 323 & 44 & S1 & $>1,5$ & $>1,5$ & 1,45 & 1,38 \\
\hline & & 301 & 49 & S2 & 1,51 & 1,44 & 1,37 & 1,31 \\
\hline & & 60 & 78 & S3 & 1,26 & 1,22 & - & - \\
\hline \multirow{4}{*}{ 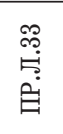 } & \multirow{4}{*}{ ЮВ } & 110 & 43 & S1 & $>1,5$ & $>1,5$ & - & - \\
\hline & & 87 & 38 & S2 & $>1,5$ & $>1,5$ & $>1,5$ & $>1,5$ \\
\hline & & 199 & 36 & S3 & $>1,5$ & $>1,5$ & $>1,5$ & $>1,5$ \\
\hline & & 57 & 59 & $\mathrm{~S} 4$ & $>1,5$ & 1,46 & - & - \\
\hline
\end{tabular}

Table 4. Summary table of calculation of the board stability factor (regulatory factor of resistance $\eta=1,3$ )

Примечание: 1) расчеты устойчивости бортов правомерны при условии отсутствия поверхностей ослабления в прибортовых массивах, при наличии поверхностей ослабления с падением в выработку откосы необходимо заоткашивать по этил поверхностям; 2 ) красным иветом выделены значения коэффициента запаса устойчивости меньше нормативного значения $(\eta=1,3)$.

Note: 1 ) calculations of side stability are legitimate, provided that there are no weakening surfaces in the pit wall arrays, in the presence of weakening surfaces with a fall in the development of slopes, it is necessary to roll them along these surfaces; 2 ) the values of the safety factor for stability less than the standard value $(\eta=1,3)$ are in red.

Оценка устойчивости откосов вскрышных уступов при изменении их основных параметров - высоты и углов наклона

Произведена оценка возможности изменения проектных параметров вскрышных уступов и борта карьера на предельном контуре при отсутствии в прибортовом массиве осложняющих факторов, каковыми могут являться поверхности ослабления, обводненность, сейсмичность, а также при их наличии.

Произведены расчеты для сдвоенных уступов суммарной высотой 30 м (проектное значение) и для строенных уступов суммарной высотой 45 м. Значения углов наклона уступов на предельном контуре в расчетах приняты в диапазоне от $55^{\circ}$ до $90^{\circ}$. Результаты расчетов устойчивости уступов приведены в табл. 5.

Согласно расчетам, результаты которых приведены в табл. 5 , устойчивость вскрышных уступов с нормативным коэффициентом запаса устойчивости $\eta=1,5$ в висячем борту: 
а) обеспечивается при следующих паралетрах (при отсутствии в прибортовол массиве поверх ностей ослабления):

- для уступов в выветрелых породах $\mathrm{H}=30 \mathrm{~m}$, $\alpha=60^{\circ}$, а также $\mathrm{H}=45 \mathrm{~m}, \alpha=55^{\circ}$;

- для уступов в невыветрелых породах $\mathrm{H}=30$ м, $\alpha=70^{\circ}$, а также $\mathrm{H}=45 \mathrm{~m}, \alpha=65^{\circ}$.

таблииа 5. Сводная таблииа расчета коэффиииента запаса устойчивости уступов (нормативный коэффици ент запаса устойчивости $\eta=1,5$ )

Table 5. Summary table of calculation of ledge stability factor ( regulatory factor of resistance $\eta=1,5$ )

\begin{tabular}{|c|c|c|c|c|c|}
\hline \multirow{2}{*}{ 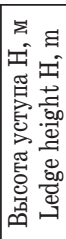 } & \multirow{2}{*}{ 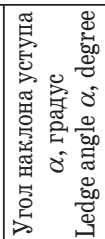 } & \multirow{2}{*}{ 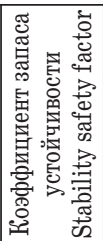 } & \multicolumn{3}{|c|}{$\begin{array}{c}\text { Коэффициент запаса устойчивости с учетом } \\
\text { Stability factor with regard to }\end{array}$} \\
\hline & & & \begin{tabular}{|c|} 
сейсмич- \\
ности \\
района \\
area seis- \\
micity
\end{tabular} & \begin{tabular}{|c|} 
уровня \\
грунтовых \\
вод \\
ground \\
water level \\
\end{tabular} & $\begin{array}{c}\text { сейсмичности } \\
\text { района и уровня } \\
\text { грунтовых вод } \\
\text { area seismicity and } \\
\text { ground water level }\end{array}$ \\
\hline \multicolumn{6}{|c|}{$\begin{array}{l}\text { Oткосы уступов в выветрелых породах висячего борта } \\
\text { Slopes of ledges in the weathered rocks of the hanging board }\end{array}$} \\
\hline 30 & 60 & $>1,5$ & $>1,5$ & $>1,5$ & $>1,5$ \\
\hline 45 & 55 & $>1,5$ & $>1,5$ & 1,5 & 1,44 \\
\hline \multicolumn{6}{|c|}{$\begin{array}{l}\text { Откосы уступов в невыветрелых породах висячего борта } \\
\text { Slopes of ledges in the unweathered rocks of the trailing board }\end{array}$} \\
\hline 30 & 70 & $>1,5$ & $>1,50$ & $>1,5$ & $>1,5$ \\
\hline 45 & 65 & $>1,5$ & $>1,5$ & 1,48 & 1,41 \\
\hline 30 & 90 & 1,32 & 1,27 & 1,24 & 1,19 \\
\hline \multicolumn{6}{|c|}{$\begin{array}{c}\text { Откосы уступов в выветрельх породах лежачего борта } \\
\text { Slopes of ledges in the weathered rocks of the lying board }\end{array}$} \\
\hline 30 & 60 & 1,37 & 1,32 & \multirow{4}{*}{$x^{\prime}$} & \multirow{4}{*}{ J } \\
\hline 30 & 80 & 0,87 & 0,84 & & \\
\hline 45 & 55 & 1,18 & 1,14 & & \\
\hline 45 & 80 & 0,78 & 0,75 & & \\
\hline \multicolumn{6}{|c|}{$\begin{array}{l}\text { Oткосы уступов в невыветрельх породах лежачего борта } \\
\text { Slopes of ledges in the unweathered rocks of the lying board }\end{array}$} \\
\hline 30 & 70 & 1,44 & 1,40 & & \\
\hline 30 & 80 & 0,97 & 0,94 & & \\
\hline 45 & 65 & 1,19 & 1,15 & & \\
\hline 45 & 80 & 0,78 & 0,75 & & \\
\hline
\end{tabular}

Примечание: 1 ) параметры уступов борта в висячем боку правомерны при отсутствии в прибортовом массиве поверхностей ос лабления; 2 ) расчет для уступов борта в лежачем боку выполнен с учетол вероятной поверхности ослабления по Главному разлому, откосы уступов не соответствуют требованиям устойчиво сти; 3 ) красным иветом выделены значения коэффициента запа са устойчивости меньше нормативного значения $(\eta=1,5)$.

Note: 1) parameters of the side ledges in the hanging side are valid without attenuation surfaces in the instrument array; 2) calculation for the ledges of the board in the recumbent side is made taking into account the probable weakening surface along the Main fault, the slopes of the ledges do not meet the requirements of stability; 3 ) the values of the safety factor less than the standard ones $(\eta=1,5)$ are highlighted in red.

\section{б) не обеспечивается:}

- для уступов высотой 45 м и углом наклона уступа $\alpha=55^{\circ}$ в выветрелых породах и в породах зоны затухающей трещиноватости при появлении любого из осложняющих факторов (коэффициент запаса устойчивости снижается до значения 1,44). Если принять во внимание тот факт, что сейсмическая активность в той или иной интенсивности в рассматриваемых горно- геологических условиях проявляется с практической регулярностью, постановка уступов на предельном контуре в висячем борту с точки зрения обеспечения безопасности, согласно геомеханическим расчетам, допустима только высотой $30 \mathrm{~m}$;

- для уступов 30 и 45 м с углами падения $\alpha=90^{\circ}$ и $\alpha=65^{\circ}$ соответственно.

Укручение угла откоса вскрышного уступа высотой $\mathrm{H}=30$ м в висячем борту более $60^{\circ}$ в зоне выветривания и более $70^{\circ}$ - в зоне затухающей трещиноватости не представляется возможным с точки зрения обеспечения безопасности работы под такими уступами. Как показали расчеты, укручение приводит к значительному снижению коэффициента запаса устойчивости (от 1,32 до 1,19, табл. 5), что может повлечь обрушение вскрышных уступов и в целом к нарушению целостности борта.

Согласно расчетам, результаты которых также приведены в табл. 5, устойчивость вскрышных уступов с нормативным коэффициентом запаса устойчивости $\eta=1,5$ даже при отсутствии в прибортовом массиве поверхностей ослабления не обеспечивается в лежачем борту:

- при укручении углов откосов вскрышных уступов высотой $\mathrm{H}=30$ м и в выветрелых породах, и в породах зоны затухающей трещиноватости до $\alpha=80^{\circ}$ и $\alpha=90^{\circ}$. Согласно геомеханическим расчетам, значение коэффициента запаса устойчивости при этом снижается до 0,94 в породах 30ны затухающей трещиноватости и до 0,84 - в породах зоны выветривания;

- высоте вскрышного уступа 45 м в выветрелых породах и в породах зоны затухающей трещиноватости при углах падения $\geq 55^{\circ}$. Значение коэффициента запаса устойчивости при этом снижается до величин от 1,14 до 0,75.

При наличии поверхностей ослабления, что свойственно породному массиву лежачего борта, устойчивость вскрышных уступов с нормативным коэффициентом запаса устойчивости $\eta=1,5$ не обеспечивается даже при проектных значениях параметров уступов на предельном контуре:

- в выветрелых породах $-\mathrm{H}=30 \mathrm{~m}, \alpha=60^{\circ}\left(\mathrm{K}_{\text {зап. уст }}\right.$ не превышает значения 1,32 );

- в вевыветрелых породах $-\mathrm{H}=30 \mathrm{~m}, \alpha=70^{\circ}\left(\mathrm{K}_{\text {зап. уст }}\right.$ не превышает значения 1,40);

Результаты расчета параметров устойчивости откосов бортов открытой горной выработки на предельном контуре

Основным условием обеспечения устойчивости рабочих бортов и уступов, в том числе и находящихся в стадии постановки их в предельное положение, является соблюдение превышения удерживающих сил над сдвигающими, действующими по наиболее напряженной поверхности в прибортовом массиве.

При окончательных расчетах устойчивости откосов бортов карьера, согласно действующим нор- 
мативныл докулентал, в исходные прочностные характеристики массива горных пород должен вводиться соответствующий коэффициент запаса устойчивости, значение которого составляет для откоса борта открытой горной выработки на предельном контуре $\eta=1,3$.

При расчетах параметров устойчивости откосов бортов использованы расчетные прочностные свойства пород прибортовых массивов (табл. 2).

Расчёты параметров бортов и уступов в условиях отсутствия неблагоприятно ориентированных поверхностей ослабления были выполнены методом алгебраического сложения сил по V схеме [17].

Схема к расчету откоса методом алгебраического сложения сил по наиболее напряженной поверхности приведена на рисунке.

Поверхность скольжения принята как плавная и криволинейная, близкая по форме к круглоцилиндрической.

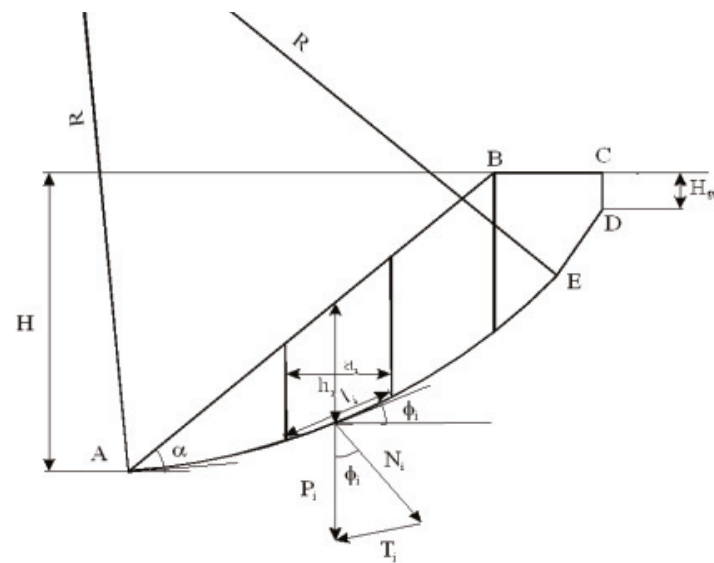

Рисунок. Схема к расчету откоса методол алгебраического сложения сил по наиболее напряженной поверхности

Figure. Scheme to slope calculation by the method of algebraic addition of forces on the most stressed surface

Результаты расчета устойчивых углов откоса бортов на предельном контуре приведены в табл. 6 .

Таблица 6. Результаты расчета устойчивых углов откоса бор тов на предельном контуре (при нормативнол коэф фициенте запаса устойчивости $\eta=1,3$ )

Table 6. Results of calculation of stable angles of repose of the sides on the upper contour (in the normative factor of resistance $\eta=1,3$ )

\begin{tabular}{|l|c|c|c|c|c|c|c|}
\hline $\begin{array}{l}\text { Высота борта Н, м } \\
\text { Воанd height H, m }\end{array}$ & 50 & 100 & 150 & 200 & 250 & 300 & 350 \\
\hline $\begin{array}{l}\text { Угл наклона борта } \alpha, \text { град } \\
\text { Board angle } \alpha, \text { degree }\end{array}$ & 54 & 50 & 50 & 49 & 49 & 48 & 45 \\
\hline
\end{tabular}

Примечание: параметры бортов правомерны при отсутствии в прибортовом массиве поверхностей ослабления. При наличии по верхностей ослабления с падением в выработку откосы необходимо заоткашивать строго по этим поверхностям.

Note: the parameters of the boards are valid in the absence of weake ning surfaces in the pit wall array. In the presence of loosening surfaces with a fall in production of slopes, it is necessary to roll back strictly along these surfaces.

\section{Анализ результатов расчета параметров} устойчивости откосов уступов на предельном контуре

Анализируя полученные результаты расчетов значений коэффициента запаса устойчивости вскрышных уступов (табл. 5) и сравнивая их величины с нормативным значением $\eta$, которое при сроке стояния уступов до 5 лет должно быть не менее 1,5, установлено следующее.

1. Геомеханическая ситуация в горном массиве висячего борта карьера свидетельствует о том, что, при условии отсутствия осложняющих факторов, устойчивость уступов на предельном контуре при их проектной высоте 30 м (сдвоенные) и высоте 45 м (строенные) и углах наклона этих уступов: соответственно для выветрелых пород $-60^{\circ}$ и $55^{\circ}$, для невыветрелых $-70^{\circ}$ и $65^{\circ}$ обеспечивается.

Однако следует отметить, что формирование уступа высотой 45 м неприемлемо ни в выветрелых породах, ни в породах зоны затухающей трещиноватости с учетом сейсмичности района и обводненности массива пород из-за снижения показателя коэффициента запаса устойчивости ниже нормативного значения.

Факт неприемлемости в данном случае актуален в связи с тем, что, по данным сейсмических наблюдений ряда последних лет, слабые толчки в массиве $\left(E<10^{4}\right.$ Дж) регистрируются ежедневно. По мнению ученых Кольского научного центра (КНЦ) [14, 20-23], это обстоятельство объясняется тем, что горные работы на близрасположенных рудниках в совокупности достигли таких объемов, которые обусловили существенное увеличение техногенного воздействия на тектонически-напряженный Хибинский массив, что и стимулирует сейсмическую активность района. Согласно выводам ученых КНЦ, которые занимаются изучением указанной проблемы, в регионе сложилось так называемое «единое геодинамическое пространство» всей системы действующих рудников и сопряженных с горным производством объектов. В пределах указанного пространства неуклонно происходят существенные изменения в естественном уровне напряженно-деформированного состояния массива, что, в свою очередь, в любой момент может обусловить возможность появления техногенной катастрофы. По этим объективным причинам пренебрежение запасом устойчивости элементов борта и борта в целом может иметь очень серьезные, непоправимые последствия.

2. Укручение откоса уступа при его высоте 30 м в породах висячего борта карьера до 80-90 в зоне затухающей трещиноватости, ведет к резкому снижению коэффициента запаса устойчивости (до $\eta=1,19)$, обусловливая отсутствие возможности обеспечения безопасности нахождения людей и механизмов под такими уступами.

3. Состояние уступов с конструктивными параметрами (угол наклонахвысота) $-70^{\circ} \times 30$ м, 
$80^{\circ} \times 30$ м, $55^{\circ} \times 45$ м и $80^{\circ} \times 45$ м в выветрелых породах лежачего борта, как показывают расчеты, характеризуется (причем, даже без учета сейсмичности района и уровня грунтовых вод) потерей их устойчивости и соответственно нарушением целостности всего борта. Последнее связано с наличием Главного разлома, являющегося первопричиной трещиноватости и сильной нарушенности массива горных пород (поверхностей ослабления). Следует отметить, что по этой причине, как показывают проверочные расчеты, произведенные по профильным линиям, не соответствуют нормативным требованиям показатели запаса устойчивости и уступов с проектными параметрами $60^{\circ} \times 30$ м в лежачем борту карьера.

4. Геомеханическая обстановка уступов с конструктивными параметрами (угол наклонахвысота) $70^{\circ} \times 30 \mathrm{M}, 80^{\circ} \times 30 \mathrm{M}, 65^{\circ} \times 45$ м и $80^{\circ} \times 45 \mathrm{M} \mathrm{в}$ невыветрелых породах лежачего борта в целом аналогична ситуации в выветрелых породах наблюдается небольшое увеличение, по сравнению с зоной повышенной трещиноватости, коэффициента запаса устойчивости до 5,0%. Однако его величины также не отвечают нормативному значению запаса устойчивости.

5. Полученные значения коэффициента запаса устойчивости уступов высотой 30 и 45 м с углом наклона $80^{\circ}$ в породах лежачего (рабочего) борта карьера свидетельствуют о существенной потере устойчивости пород и соответственно о недостижимости требуемого уровня безопасности ведения горных работ.

6. Таким образом, с целью обеспечения сохранности борта, безопасности ведения горных работ и исключения опасных деформаций прибортового массива в условиях рассматриваемого карьера (месторождения), где лежачий борт является рабочим, несущим развитую транспортную систему, рассмотрение предельного (наихудшего) случая (откосы уступов в выветрелых породах), когда увеличение высоты уступа до 45 м и угла его наклона более $55^{\circ}$ для выветрелых пород и $65^{\circ}$ - для невыветрелых, является недопустимыми. При этом в рассматриваемых горно-геологических условиях также не допускается укручение откоса уступа более $60^{\circ}$ для выветрелых и $70^{\circ}$ - для невыветрелых пород при его высоте 30 м.

\section{Выводы}

После детального изучения горно-геологических условий месторождения «Олений ручей» и существующих данных о физико-механических свойствах горных пород, слагающих массив рассматриваемого месторождения, полученных в результате геологоразведки и исследований, проводимых в течении длительного периода времени учеными КНЦ, в ходе работы авторами проведен целый ряд расчетов и построений, целью которых была геомеханическая оценка параметров устойчивости откосов бортов и их элементов, а также по- иск возможности изменения проектных параметров вскрышных уступов и борта карьера на предельном контуре. Результаты проведенной работы позволяют сделать следующие выводы.

1. Понятно, что экономические факторы обусловливают желание недропользователя укрутить углы откосов бортов с целью сокращения объемов вскрышных работ. Однако все результаты геомеханических расчетов, произведенные в настоящей работе, особенно для лежачего борта, актуальны при обеспечении безопасности работ на основании существующей нормативно-законодательной базы, а также в случае соответствия расчетных значений коэффициента запаса устойчивости бортов карьера и вскрышных уступов их нормативному значению. Для горно-геологических условий месторождения «Олений ручей» этот факт особенно актуален по следующим важным обстоятельствам:

а) исследования и данные о физико-механических и прочностных свойствах вскрышных пород зоны интенсивной трещиноватости в геологических материалах отсутствуют, а взятые аналоги не являются гарантией полной идентичности со свойствами пород рассматриваемого месторождения, тем более, что самым слабым звеном в строении выработанного пространства карьера «Олений ручей» является лежачий борт, в котором располагается Главный разлом, который более всего влияет на прочностные свойства пород, слагающих этот борт, и этот фактор сам по себе уникален. По этой причине расчеты, опирающиеся на аналоговые характеристики из других горно-геологических условий, априори не могут на 100 \% гарантировать точность и, соответственно, безопасность;

б) устойчивость бортов, формируемых при отработке запасов апатит-нефелинового месторождения «Олений ручей», находится под воздействием целого комплекса серьезных факторов природного происхождения: структурно-тектоническое строение прибортового массива (особенно в лежачем борту), его обводненность и сейсмичность.

2. Поверочные расчеты устойчивости откосов бортов на проектном предельном контуре и по варианту отработки по характерным профильным линиям (табл. 4) показали, что их устойчивость в основном обеспечивается нормативным коэффициентом запаса устойчивости $(\eta=1,3)$. Исключением являются участки северо-западного борта в висячем боку (в его нижней части) по пр.л. 29 и 33 - соответственно.

3. Выполненными в настоящей работе геомеханическими расчетами определены параметры откосов бортов на предельном контуре, значения которых приведены в табл. 6. Полученные значения параметров правомерны при отсутствии в прибортовом массиве поверхностей ослабления. При наличии поверхностей ослабления с 
падением в выработку откосы необходимо заоткашивать строго по этим поверхностям.

\section{Заключение}

Результаты выполненных исследований и проведенные расчеты для условий лежачего борта показали, что нормативный коэффициент запаса устойчивости уступов на предельном контуре может быть обеспечен только в том случае, если они заоткашиваются по поверхностям ослабления (по падению Главного разлома или др.), подрезка которых недопустима.

Рекомендованы параметры откосов бортов карьера и их элементов на предельном контуре. Поверочные расчеты устойчивости на проектном

\section{СПИСОК ЛИТЕРАТУРЫ}

1. Козырев А.А., Семёнова И.Э., Аветисян И.М. Геомеханическое обоснование безопасной отработки стыковочных зон на Юкспорском месторождении // Горный информационно-аналитический бюллетень. - 2015. - № 4. - С. 84-92.

2. Калюжный А.С. Определение параметров нарушенной зоны и объёмов потенциальных вывалов для условий карьера «0лений ручей» // Горный информационно-аналитический бюллетень. - 2016. - № 7. - С. 403-412.

3. Рыбин В.В., Потапов Д.А., Калюжный А.С. Районирование карьерного поля месторождения Олений ручей по глубине с использованием геомеханической классификации профессора Д. Лобшира // Проблемы недропользования. - 2014. - № 1. C. $44-52$.

4. Рыбин В.В., Калюжный А.С., Потапов Д.А. Геомеханическое обоснование параметров борта карьера на месторождении «0лений ручей» и мониторинг его устойчивости // Мониторинг природных и техногенных процессов при ведении горных работ. Геомеханический мониторинг геологической среды природотехнических систем: Труды международной конференции. - Апатиты, 2013. - С. 180-187.

5. Dowling J., Beale G., Bloom J. Designing a large scale pit slope depressurization system at Bingham canyon // Reliable Mine Water Technology: International mine water association annual conference. - Denver, Colorado, USA, 2013. - V. I. - P. 119-125.

6. Risk evaluation of slope failure at the Chuquicamata mine / A. Tapia, L.F. Contreras, M. Jefferies, O. Steffen // Slope Stability 2007. Proc. of 2007 International Symposium on rock slope stability in open pit mining and civil engineering. Ed. by Y. Potvin. - Perth Australia: Australian Centre for Geomechanics, 2007. - P. 477-495.

7. The Transition from open pit to underground mining: An Unusual Slope Failure Mechanism at Palabora / R.K. Brummer, H. Li, A. Moss, T. Casten // Proc. of international symposium on stability of rock slopes in open pit mining and civil engineering. $-\mathrm{Ca}$ pe Town, 2006. - P. 411-420.

8. Wines D.R., Lilly P.A., Measurement and analysis of rock mass discontinuity spacing and frequency in part of the Fimiston open pit operation in Kalgoorie, Western Australia: a case study // International journal of rock mechanics \& mining science. - 2002. V. 39. - № 5. - P. 589-602.

9. Руководство по проектированию бортов карьера / под ред. Д. Рид, П. Стейси / Пер с англ. - Екатеринбург: Правовед, 2015. - $544 \mathrm{c}$.

10. Laubcher D.H. A geomechanics classification system for rating of rock mass in mine design // Journal South Africa inst. of mining and metallurgy. - 1990 - V. 90. - № 10. - P. 257-273. предельном контуре и по рекомендованному варианту отработки показали, что их устойчивость в основном обеспечивается нормативным коэффициентом запаса устойчивости $(\eta=1,3)$.

Последующая отработка месторождения возможна по варианту, который предусматривает максимальное вовлечение в отработку прибортовых и подкарьерных запасов в существующих границах горного отвода карьера из условий обеспечения заезда с поверхности на самый нижний горизонт, в том числе вовлечение в отработку части подкарьерных запасов рудных тел, прослеженных эксплуатационной разведкой в юго-западной части поля рудника с углубкой проектных границ на 15-45 м, а в северо-восточной - до гор. + 135 м.

11. Kozyrev A.A., Semenova I.E., Zemtsovskiy A.V. Complex geomechanical research of the rock mass during underground mining in tectonically stressed rock mass, the Oleniy Ruchey deposit // Proc. of the 3' SinoRussian Joint Scientific Technical Forum on Deep level Rock Mechanics and Engineering. - China, Nanjing, 2013. - P. 20-29.

12. Laubcher D.H., Jacubec J. The MRMR (Mining Rock Mass Rating) rock mass classification for jointed rock masses // Foundations for Design. - 2000. - P. 475-481.

13. Haines A., Terbrugge P.J. Preliminary estimation of rock slope stability using rock mass classification systems // Proc. $7^{\text {th }}$ Cong. on mechanics. ISRM. - Aachen, Germany. Ed. by W. Wittke. Publ. Balkema, Rotterdam. - 1991. - V. 2. - P. 887-892.

14. Отчет 0 научно-исследовательской работе «Инженерно-геологические условия разработки апатитонефелинового месторождения Олений ручей». - Апатиты: Горный институт Кольского научного центра Российской академии наук, 2009. -160 c.

15. Отчет о научно-исследовательской работе «Регламент на укручение бортов карьера месторождения апатит-нефелиновой руды Олений ручей». - Апатиты: Горный институт Кольского научного центра Российской академии наук, 2012. - 175 c.

16. Отчет о научно-исследовательской работе «Определение основных параметров физико-механических свойств горных пород по разрезу структурной инженерно-геологической скважины для оценки геомеханических условий проходки главного ствола». - Апатиты: Горный институт Кольского научного центра Российской академии наук, 2013. - 142 c.

17. Методические указания по определению углов наклона бортов, откосов уступов и отвалов строящихся и эксплуатируемых карьеров. - Л.: Всесоюзный научно-исследовательский институт горной геомеханики и маркшейдерского дела (ВНИМИ), $1972 .-160 \mathrm{c}$

18. СНиП 11-7-81* «Строительство в сейсмических районах». М.: Министерство строительства и жилищно-коммунального хозяйства РФ, 2014. - 131 с.

19. Отчет о научно-исследовательской работе «Разработка основных технологических решений (регламента) для вскрытия и отработки прибортовых и подкарьерных запасов верхнего яруса месторождения «Олений ручей». - Новосибирск: Институт горного дела Сибирское отделение Российской академии наук (ИГД СО РАН), 2018. - 180 с.

20. Лобанов Е.А., Чайкин Д.А., Меньшиков П.Ю. Разработка технологических решений вскрытия и отработки прибортовых и подкарьерных запасов апатито-нефелиновых руд // Фундаментальные и прикладные науки в горном деле. - 2018. T. 5. - № 1. -C. 88-93.

21. Калюжный А.С., Земцовский А.В. Исследование напряженнодеформированного состояния массива пород в окрестности 
карьерной выемки месторождения «Олений ручей» // Труды Ферсмановской научной сессии Горного института Кольского научного центра Российской академии наук. - 2017. - № 14. C. 278-282.

22. Козырев А.А., Семенова И.Э., Журавлева О.Г. Влияние природных и техногенных факторов на проявление сейсмичности на рудниках Хибинского массива // Триггерные эффекты в геосистемах: тезисы докладов IV Всероссийской конференции с международным участием. - М.: ГЕОС, 2017. - С. 46-47.
23. Kozyrev A.A., Semenova I.E., Zemtsovskiy A.V. Investigation of geomechanical features of the rock mass in mining of two contiguous deposits under tectonic stresses // Procedia Engineering. 2017. - V. 191. - P. 324-331. DOI: $10.1016 /$ j.proeng.2017.05.188

Поступила 21.01.2019 2.

\section{Информация об авторах}

Немова H.A., кандидат технических наук, старший научный сотрудник лаборатории «Открытые горные работы» Института горного дела им. Н.А. Чинакала Сибирского отделения Российской академии наук.

Бельш T.A., инженер лаборатории «Открытые горные работы», Института горного дела им. Н.А. Чинакала Сибирского отделения Российской академии наук. 


\title{
GEOMECHANICAL ESTIMATION OF STABILITY PARAMETERS OF PIT SLOPE SCALE AND BATTERS WHEN DEVELOPING THE APATITE-NEPHELINE ORE DEPOSIT "OLENIY RUCHEY»
}

\author{
Natalya A. Nemova',
}

nemova-nataly@mail.ru

\author{
Tatyana A. Belsh', \\ tata0303@bk.ru
Institute of Mining, Siberian Branch, Russian Academy of Sciences, 54, Krasny avenue, Novosibirsk, 630091, Russia.

The relevance of the research is caused by the need to conduct safely mining in quarries with a depth of over $360 \mathrm{~m}$. Increasing production volumes is possible with significant deepening; to reduce the amount of overburden it is necessary to twist the side slopes and ledges. To solve this issue, it is necessary to know the geomechanical situation of the benches and sides both on the limiting contour and when changing their basic parameters - height and inclination angle.

The main aim of the research is to analyze the mining and geological conditions of the "Oleniy ruchey» deposit and the existing data on physicomechanical properties of the rocks forming the massif of the deposit in question, to calculate and check the stability of the slopes of the pit's edges on the marginal contour and to find the possibility of tilting the sides and overburden ledges during mining.

object: large deposit of apatite-nepheline ores "Oleniy ruchey».

Methods: mining and geological analysis of the "Oleniy ruchey» deposit and analysis of existing data on the physicomechanical properties of rocks composing the array of the deposit in question, analytical calculations of the stability of slope elements.

Results. The authors have obtained the data of calculations of slope stability without attenuation surfaces in the near-side massif of the border in the hanging side of the ore deposit (hanging side) and taking into account the angle of incidence of the Main fault at the angle of $40-45^{\circ}$ while forming the open-pit side in the bottom wall (recumbent board), and taking into account as well the seismicity of the area and groundwater level. The parameters of the slopes of the sides of the limit circuit were determined. The obtained values of the parameters are valid in the absence of weakening surfaces in the near-surface array. In the presence of loosening surfaces with a fall in the production of slopes, it is necessary to roll back strictly along these surfaces.

\section{Key words:}

Quarry, mine, pit, batter, slope, slope (side, ledge), pit wall reserves, rock mass, geomechanical substantiation, stress-strain state, stability, safety factor, destruction, development system, safety, efficiency.

\section{REFERENCES}

1. Kozyrev A.A., Semenov I.E., Avetisyan I.M. Geomechanical substantiation of safe mining of connecting zones at the Yuksporsky deposit. Mining Information and Analytical Bulletin, 2015, no. 4, pp. 84-92. In Rus.

2. Kalyuzhny A.S. Determination of the parameters of the disturbed zone and the volumes of potential dumps for the conditions of the Oleniy Ruchey quarry. Mining Information and Analytical Bulletin, 2016, no. 7, pp. 403-412. In Rus.

3. Rybin V.V., Potapov D.A., Kalyuzhny A.S. Zoning of the open pit mine at Oleniy Ruchey deposit by depth using the geomechanical classification of professor D. Lobshire. Problems of Subsoil Use, 2014, no. 1, pp. 44-52. In Rus.

4. Rybin V.V., Kalyuzhny A.S., Potapov D.A. Geomekhanicheskoe obosnovanie parametrov borta karera na mestorozhdenii «Oleniy ruchey» i monitoring ego ustoychivosti [Geomechanical substantiation of the pit's board parameters at the Oleniy Ruchey deposit and monitoring its sustainability]. Monitoring prirodnykh i tekhnogennykh protsessov pri vedenii gornykh rabot. Geomekhanichesky monitoring geologicheskoy sredy prirodotekhnicheskikh system. Trudy mezhdunarodnoy konferentsii [Proceedings of the International conference. Monitoring of natural and man-made processes in mining. Geomechanical monitoring of the geological environment of environmental systems]. Apatity, 2013. pp. 180-187.

5. Dowling J., Beale G., Bloom J. Designing a large scale pit slope depressurization system at Bingham canyon. International Mine Water Association Annual Conference. Reliable Mine Water Technology. Denver, Colorado, USA, 2013. Vol. I, pp. 119-125.

6. Tapia A., Contreras L.F., Jefferies M., Steffen 0. Risk evaluation of slope failure at the Chuquicamata mine. Slope Stability 2007. Proc. of 2007 International Symposium on Rock Slope Stability in
Open Pit Mining and Civil Engineering. Ed. by Y. Potvin. Australia, Australian Centre for Geomechanics, 2007. pp. 477-495.

7. Brummer R.K., Li H., Moss A., Casten T. The Transition from open pit to underground mining: An Unusual Slope Failure Mechanism at Palabora. Proc. of International symposium on stability of rock slopes in open pit mining and civil engineering. Cape Town, 2006. pp. 411-420.

8. Wines D.R., Lilly P.A., Measurement and analysis of rock mass discontinuity spacing and frequency in part of the Fimiston open pit operation in Kalgoorie, Western Australia: a case study. International Journal of Rock Mechanics \& Mining Science, 2002, vol. 39 , no. 5, pp. 589-602.

9. Rukovodstvo po proektirovaniyu bortov karyera [Guidelines for open pit slope design]. Eds. J. Read, P. Stasey. Translated from English. Ekaterinburg, Pravoved Publ., 2015. 544 p.

10. Laubcher D.H. A geomechanics classification system for rating of rock mass in mine design, Journal South Africa Inst. of Mining and Metallurgy, 1990, vol. 90, no. 10, pp. 257-273.

11. Kozyrev A.A., Semenova I.E., Zemtsovskiy A.V. Complex geomechanical research of the rock mass during underground mining in tectonically stressed rock mass, the Oleniy Ruchey deposit. Proc. of the 3'SinoRussian Joint Scientific Technical Forum on Deep level Rock Mechanics and Engineering. China, Nanjing, 2013. pp. 20-29.

12. Laubcher D.H., Jacubec J. The MRMR (Mining Rock Mass Rating) rock mass classification for jointed rock masses. Foundations for Design, 2000, pp. 475-481.

13. Haines A., Terbrugge P.J. Preliminary estimation of rock slope stability using rock mass classification systems. Proc. $7^{\text {th }}$ Cong. on mechanics. ISRM. Aachen, Germany. Ed. by W. Wittke. Rotterdam, Publ. Balkema, 1991. Vol. 2, pp. 887-892. 
14. Otchet o nauchno-issledovatelskoy rabote «Inzhenerno-geolo gicheskie usloviya razrabotki apatitonefelinovogo mestorozhdeniya Oleniy ruchey» [Report on the research work «Engineering and geological conditions for development of the Oleniy Ruchey apatite-nepheline deposit»]. Apatity, Mining Institute of the Kolskiy Scientific Center Russian Academy of Sciences Publ., 2009. $160 \mathrm{p}$.

15. Otchet o nauchno-issledovatelskoy rabote «Reglament na ukruchenie bortov karera mestorozhdeniya apatit-nefelinovoy rudy Oleniy ruchey» [Report on the research work "Regulations for the tilting of the pit sides of the pit of the Oleniy Ruchey apatite-nepheline ore deposit»]. Apatity, Mining Institute of the Kolskiy Scientific Center Russian Academy of Sciences Publ., 2012. 175 p.

16. Otchet o nauchno-issledovatelskoy rabote «Opredelenie osnounykh parametrou fiziko-mekhanicheskikh svoystu gornykh porod po razrezu strukturnoy inzhenerno-geologicheskoy skvazhiny dlya otsenki geomekhanicheskikh usloviy prokhodki glaunogo stvola» [Report on the research work «Determination of the main parameters of the physicomechanical properties of rocks from the section of a structural engineering-geological well for assessment of the geomechanical conditions of penetration of the main wellbore»]. Apatity, Mining Institute of the Kolskiy Scientific Center Russian Academy of Sciences Publ., 2013. 142 p.

17. Metodicheskie ukazaniya po opredeleniyu uglov naklona bortov, otkosov ustupov i otvalov stroyashchikhsya i ekspluatiruemykh karerov [Guidelines for determination of the inclination angles of the sides, slopes of batters and dumps under construction and exploited quarries]. Leningrad, Research Institute of Mining Geomechanics and Surveying Publ., $1972.160 \mathrm{p}$.

18. SNIP 11-7-81. Stroitelstvo $v$ seysmicheskikh rayonakh [SRG 11-7-81* Construction in seismic areas]. Moscow, Ministry of construction and housing and communal services RF Publ., 2014. $131 \mathrm{p}$.
19. Otchet o nauchno-issledovatelskoy rabote «Razrabotka osnovnykh tekhnologicheskikh resheniy (reglamenta) dlya vskrytiya i otrabotki pribortovykh i podkarernykh zapasov verkhnego yarusa mestorozhdeniya Oleniy ruchey» [Report on the research work «Development of the main technological solutions (regulations) for opening and testing of pit bottom and pit wall reserves of the upper tier of the Oleniy Ruchey deposit»]. Novosibirsk, Institute of Mining Siberian Branch Russian Academy of Sciences Publ., 2018. $180 \mathrm{p}$.

20. Lobanov E.A., Chaykin D.A., Menshikov P.Yu. Development of technological solutions for the opening and mining of pit wall and pit bottom reserves of apatite-nepheline ores. Fundamental and applied Sciences in mining, 2018, vol. 5, no. 1, pp. 88-93. In Rus.

21. Kalyuzhny A.S., Zemtsovskiy A.V. Investigation of the stressstrain state of the rock mass in the vicinity of the quarry excavation of the Oleniy Ruchey deposit. Proc. of the Fersmanousky Scientific Session of the Mining Institute of the Kola Scientific Center of the Russian Academy of Sciences, 2017, no. 14, pp. 278-282. In Rus.

22. Kozyrev A.A., Semenova I.E., Zhuravleva 0.G. Vliyanie prirodnykh i tekhnogennykh faktorov na proyavlenie seysmichnosti na rudnikakh Hibinskogo massiva [The influence of natural and technogenic factors on manifestation of seismicity in the mines of the Khibiny massif]. Triggernye effekty $v$ geosistemakh. Tezisy dokladov IV Vserossiyskoy konferentsii s mezhdunarodnym uchastiem [Trigger effects in geosystems. Abstracts of the IV AllRussian Conference with international participation]. Moscow, GEOS Publ., 2017. pp. 46-47.

23. Kozyrev A.A., Semenova I.E., Zemtsovskiy A.V. Investigation of Geomechanical Features of the Rock Mass in Mining of Two Contiguous Deposits under Tectonic Stresses. Procedia Engineering, 2017, vol. 191, pp. 324-331.

Received: 21 January 2019.

\section{Information about the authors}

Natalya A. Nemova, Cand. Sc., senior researcher, Institute of Mining Siberian Branch Russian Academy of Sciences.

Tatyana A. Belsh, engineer, Institute of Mining Siberian Branch Russian Academy of Sciences. 